\title{
Predator-mediated genotypic shifts in a prey population: experimental evidence
}

\author{
Joanna Pijanowska*, Lawrence J. Weider, Winfried Lampert \\ Max-Planck-Institut für Limnologie, Postfach 165, D-24306 Plön, Germany \\ Received: 5 April 1993 / Accepted: 12 July 1993
}

\begin{abstract}
We demonstrate the effect of fish predation on genotype frequencies in a laboratory population composed of two Daphnia magna clones, with historically contrasting exposures to fish predation. The two clones differed in their responsiveness to predation via differential avoidance/escape behavior. The clone which coexists with fish in nature is more responsive to the presence of a fish predator, while the clone not exposed to fish predation does not exhibit the defensive reaction. Fish caused a rapid (within $18 \mathrm{~h}$ ) and significant shift in Daphnia clonal composition, from $1: 1$ to $8: 1$, in favor of the responsive clone. Genotype-specific defensive abilities (modus defendi) can contribute greatly to the phenomenon of genotype replacement under selective predation.
\end{abstract}

Key words: Daphnia - Vertical migration - Predatorinduced behavior - Clonal replacement

As a major source of mortality in many natural populations (Elton 1927), predation can be a potent selective factor shaping avoidance and escape behavioral responses in prey populations (e.g., Sih 1987; Lima and Dill 1990). Differences among genotypes with respect to their responsiveness to predation can enhance differences in their short-term survival probabilities within a prey population. The effects of natural selection in the wild have been demonstrated for numerous traits among a wide variety of plants and animals (Endler 1986). Though predation has been invoked as a selective agent in causing evolutionary changes in many cases, direct selection for behavioral traits has only occasionally been reported in natural populations (but see Fawcett 1984; Dickman 1992).

\footnotetext{
* Permanent address: Department of Hydrobiology, University of Warsaw, Nowy Swiat 67, 00046 Warsaw, Poland

Correspondence to: J. Pijanowska
}

In this study, we investigated the effect of predation on microevolutionary changes within a prey population, based on behavioral traits. We demonstrate the effect of fish predation on genotype frequencies in a laboratory population of the freshwater parthenogenetic cladoceran Daphnia magna Straus. We non-randomly selected two genetically distinct, but morphologically indistinguishable clones that differed in their past exposure to fish predation. One of them originates from a fishless shallow pond near Warsaw (Poland) and for the past 12 years has not been exposed to any predation in the laboratory (clone W). The second (clone B) originates from the Großer Binnensee (Schleswig-Holstein, Germany), a shallow brackish lake inhabited by fish. It has been recently reported that clones of another cladoceran, Daphnia pulex, isolated from ponds inhabited by invertebrate predators showed significantly greater morphological response to the presence of predators than clones from predator-free ponds (Parejko and Dodson 1991). It therefore seemed plausible that clone B, which shared its recent evolutionary history with predators, would be more efficient in terms of anti-predator behavioral defence and, as a consequence, would be exterminated at a slower rate. Various defensive behavioral responses to fish predation (e.g. vertical and horizontal distribution patterns, direct escape abilities) have recently been examined in these two clones (Pijanowska et al., unpubl. data), and the predicted differences in their behavior were indeed found.

Among a broad variety of defensive responses by planktonic animals, avoiding surface waters in daytime is recognized as an efficient mechanism that can reduce the risk of predation by visual predators, by using a spatial refuge in deep water during the day (for recent reviews see Lampert 1989, 1993). There is growing empirical evidence that this behavior can be induced by chemical compounds released into the environment by a potential predator, without accompanying selection/ mortality (for review see Pijanowska 1993). The comparison of vertical distribution patterns between the two clones in a system of single, 1-m-long plexiglas tubes 
illuminated from above (Dawidowicz 1993), under standardized conditions in fish-free water and water containing fish exudates (Loose et al. 1992) revealed that these two clones differed remarkably in their behavioral reactions to the chemical presence of a predator (Pijanowska and Dawidowicz, unpubl. data). In fish water, Daphnia from clone B showed a clear tendency to stay deeper during the day, while Daphnia from clone W remained permanently at the surface: mean day depth of clone B animals ( $42.5 \pm 8.9 \mathrm{~cm}$; mean $\pm 1 \mathrm{SD})$, differed from the mean day depth of clone W $(3.7 \pm 1.2 \mathrm{~cm})$ at $P<0.0001$ (Mann-Whitney $U$-test). It was shown elsewhere (Dawidowicz and Loose 1993; Loose et al. 1992) that in the same experimental system Daphnia magna from the Binnensee can migrate even deeper, reaching the bottom of the tubes. Mean day depths in fish-free water were $3.8 \pm 0.8 \mathrm{~cm}$ and $2.2 \pm 0.5 \mathrm{~cm}$ for clones $B$ and $W$, respectively, and did not differ significantly (Pijanowska and Dawidowicz, unpubl. data). Though these clones do not coexist in the wild, they offer a suitable target for shortterm selection by a fish predator since they express two distinct clone-specific behaviors.

\section{Methods}

Six cylindrical plastic containers $(75 \mathrm{~cm}$ high, $50 \mathrm{~cm}$ upper diameter, 1501 capacity) were filled with lake water filtered through a $10-\mu \mathrm{m}$ filter. Water temperature was $18.1 \pm 0.2^{\circ} \mathrm{C}($ mean $\pm 1 \mathrm{SD})$, and light at the surface ranged from 0.16 to $0.18 \mu \mathrm{E} \mathrm{m}^{-2} \mathrm{~s}^{-1}$. A plastic mesh-screen (4 mm mesh size) was installed at mid-depth in each container; Daphnia could easily swim through the screen. By restricting the movement of fish to the upper layer, we created a bottom refuge for those Daphnia that could avoid predation at the surface by downward migration. In three of the six containers, three fish (sunbleaks, Leucaspius delineatus L., of $6.5 \pm 0.9 \mathrm{~cm}$ mean total length) per container were allowed to swim freely for $48 \mathrm{~h}$. They were transferred daily for about $1 \mathrm{~h}$ to glass aquaria, and fed with approximately 100 Daphnia per fish. After $48 \mathrm{~h}$, fish were removed and 600 Daphnia (1:1 mixture of clones B and $\mathrm{W}$, mean individual size at the beginning of the experiment $1.32 \pm 0.22 \mathrm{~mm}$ and $1.31 \pm 0.21 \mathrm{~mm}$, mean $\pm 1 \mathrm{SD}$, respectively) were introduced to each of the six containers, and for the next $48 \mathrm{~h}$, they were allowed to distribute in the water column. Daphnia were fed with a suspension of the green alga Scenedesmus acutus at a concentration of $1 \mathrm{mg} \mathrm{C}$ $1^{-1}$, adjusted daily in each of the six containers. After $48 \mathrm{~h}$, a single fish was introduced to each of those three containers which had previously held fish; they were allowed to feed for $18 \mathrm{~h}(6 \mathrm{~L}: 6 \mathrm{D}: 6 \mathrm{~L})$. The three control populations were exposed neither to the fish cue nor to predatory pressure, to compare Daphnia distributions with and without fish and to provide an estimate of background mortality not caused by predation.

All survivors (at the end of the experiment, mean Daphnia size was $1.56 \pm 0.02 \mathrm{~mm}$ in clone $\mathrm{B}$, and $1.47 \pm 0.07 \mathrm{~mm}$ in clone $\mathrm{W}$, means $\pm 1 \mathrm{SD}$ ) in each of the six containers were harvested from above the screen and then counted. After removing the screen, the remaining animals were harwested from below. Final clonal frequencies were obtained using cellulose acetate gel electrophoresis (Hebert and Beaton 1989). The glutamate-oxaloacetate transferase (GOT, EC.2.6.1.1) locus served as a diagnostic marker. All survivors in the fish containers and 96 animals per control container from above and from below the screen were assayed separately.

In addition to the spatial distribution patterns, we examined the direct escape capability of Daphnia from both clones assuming that a predator would less frequently attack the more evasive prey. Daphnia of each clone (mean size of animals was $1.33 \pm 0.02 \mathrm{~mm}$ in clone $B$, and $1.42 \pm 0.16$ for clone W) were exposed for $24 \mathrm{~h}$ to water that for the previous $24 \mathrm{~h}$ had contained two fish per $10 \mathrm{l}$, fed with 100 Daphnia each. Daphnia were fed with a Scenedesmus acutus

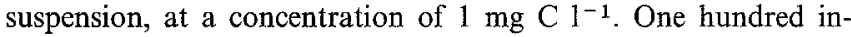
dividuals of each clone were offered to a single fish (sunbleak, $6.0-7.0 \mathrm{~cm}$ total length) in a $4.5-1$ glass jar (three replicates per clone). To minimize the inter-individual variation in feeding behavior, all six fish were starved for $24 \mathrm{~h}$ and then, before the experiment, fed with 100 Daphnia each. The number of successful attacks was noted during the first 10 min of feeding trials, starting with the first successful attack. The number of survivors was counted after $30 \mathrm{~min}$.

\section{Results and discussion}

Fish-mediated mortality ranged from 56.2 to $83.7 \%$ $(72.4 \pm 14.3 \%$ on average, mean $\pm 1 \mathrm{SD})$. Regardless of the strength of predatory impact, the relative survival rate of clone $\mathrm{B}$ was up to 8 times more than that of clone W (Fig. 1). Fish caused a rapid (within $18 \mathrm{~h}$ ) and significant shift in Daphnia clonal composition. Thus, the final clonal proportion $(8 \mathrm{~B}: 1 \mathrm{~W})$ differed significantly from initial proportion (1B:1W) at $P<0.001,\left(\chi^{2}\right.$ goodness of fit).

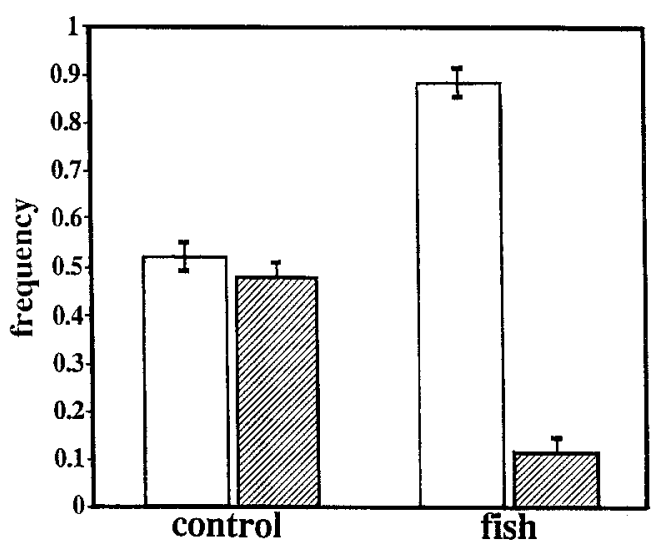

Fig. 1. The effect of $18 \mathrm{~h}$ fish predation on the proportions of two Daphnia clones offered in the same initial numbers at the start of the experiment (means $\pm 95 \% \mathrm{CI}$ ). Open bars: Daphnia clone B from a lake with fish (Binnensec); shaded bars: Daphnia clone W, which had not been exposed to predation for at least 12 years

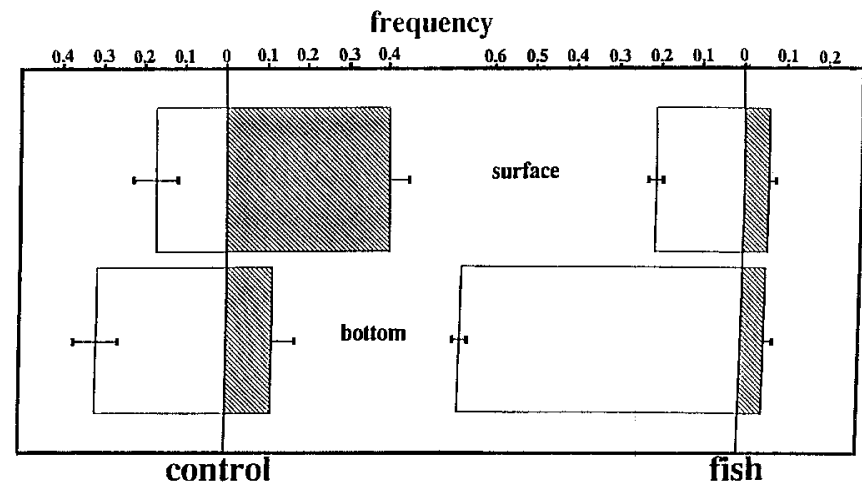

Fig. 2. Final vertical distributions of two Daphnia clones after $18 \mathrm{~h}$ of fish feeding, shown as surface (above the screen) and bottom (below the screen) fractions of total Daphnia densities in the control and fish treatments (means $+95 \% \mathrm{CI}$ ). Open bars: clone B; shaded bars: clone $\mathrm{W}$ 
Clone-specific behavior must have affected predator choice [average value of Manly's $\alpha$ preference index (Manly 1974) for clone $B, \alpha_{B}=0.284 \pm 0.116$, differed from $a_{\mathrm{W}}=0.718 \pm 0.114$ at $P<0.0098$, two-sample $t$-test].

The greater survivorship of Daphnia from clone B can be ascribed to their strong tendency to remain deeper (below the screen) in the water column (Fig. 2), which was enhanced in the presence of fish.

Experimentally tested short-term survivorship also differed significantly between the two clones $(14 \pm 5 \%$ survivors after $30 \mathrm{~min}$ of fish feeding in clone $\mathrm{B}$ compared to $5 \pm 1 \%$ in clone $\mathrm{W}$, means $\pm 1 \mathrm{SD}, P<0.05$, two-sample $t$-test, after correction for unequal variances). Daphnia from clone B showed significantly greater evasiveness when exposed to fish than animals from the same size range from clone $\mathrm{W}$ (mean $\pm 1 \mathrm{SD}$ number of successful attacks within the first $10 \mathrm{~min}$ of fish feeding trials was $22 \pm 4$ for clone $B$, which differed from $47 \pm 7$ for clone $W$ at $P<0.01$, two-sample $t$-test). When a predator is foraging on clone B animals, it takes it more than twice as long to successfully complete an attack sequence. Thus both, vertical distribution patterns and direct escape capability can confer resistance to fish predators and promote greater survivorship of clone B animals.

The inter-clonal differences in responsiveness to predation via differential avoidance/escape behavior are most probably related to the clones' contrasting experience of predation in the wild; i.e., Daphnia from clone $B$ which coexist with fish in nature are more responsive to the presence of fish than animals from clone W. Gliwicz (1986) suggested that there should be a high probability of extinction of non-responsive genotypes when they are exposed to a predator. In the absence of simultaneous disruptive selection on other characters, natural selection will then result in the reduction of genetic variance within populations (Endler 1986; Spitze 1991). However, the outcome of selection can be reversed within a few generations when high metabolic costs are associated with predator avoidance. In our study, we measured one important fitness component, i.e., "viability fitness". The energetic costs of defense can strongly influence the second constituent of individual fitness, "reproductive fitness" (Janzen 1981). In the wild, where the coexistence of responsive and non-responsive ethotypes/genotypes has been shown to occur in Daphnia populations (Weider 1984, 1985; de Meester 1990), genotype-specific defensive abilities (modus defendi) and genotype-specific costs of defence can contribute greatly to the phenomenon of genotype replacement under selective predation. The maintenance of genetic variation in prey populations may be to a large extent attributed to differential viability and reproductive fitness of different ethotypes under changing predation regimes. An obvious next step to further understanding of the phenomenon of genotypic replacement under selective predation would be to study the effect of predatory pressure on a mixture of behaviorally distinct genotypes isolated from the same population, and estimate inter-genotype differences in fitness components.

Acknowledgements. We kindly ackowledge the helpful advises of Carsten Loose at various stages of this study. We thank Eva Geissler and Andreas Heinken for their excellent technical assistance, and anonymous reviewers for their comments on an earlier version of this paper.

\section{References}

Dawidowicz P (1993) Diel vertical migration in Chaoborus flavicans: population patterns vs individual tracks. Arch Hydrobiol Beih Erg 39:19-28

Dawidowicz P, Pijanowska J, Ciechomski K (1990) Vertical migration of Chaoborus larvae is induced by the presence of fish. Limnol Oceanogr 35:1631-1637

Dickman CR (1992) Predation and habitat shift in the house mouse, Mus domesticus. Ecology 73:313-322

Elton CS (1927) Animal ecology. Sedgewick \& Jackson, London

Endler JA (1986) Natural selection in the wild. Princeton University Press, Princeton

Gliwicz ZM (1986) Predation and the evolution of vertical migration behaviour in zooplankton. Nature 320:746-748

Fawcett MH (1984) Local and latitudinal variation in predation on an herbivorous marine snail. Ecology 65:1214-1230

Janzen DH (1981) Evolutionary ecology of personal defence. In: Townsend CR, Calow P (eds) Physiological ecology: an evolutionary approach to resource use. Sinauer, pp 145-164

Hebert PDN, Beaton MJ (1989) Methodologies for allozyme electrophoresis using cellulose acetate electrophoresis: a practical handbook. Helena Laboratories, Beaumont

Lampert W (1989) The adaptive significance of diel vertical migration of zooplankton. Funct Ecol 3:21-27

Lampert W (1992) Ultimate causes of diel vertical migration of zooplankton: new evidence for the predator avoidance hypothesis. Arch Hydrobiol Beih Erg 39:79-88

Lima SL, Dill LM (1990) Behavioral decisions made under the risk of predation: a review and prospectus. Can J Zool 68:619-640

Loose CJ, Elert E von, Dawidowicz P (1992) Chemically-induced diel vertical migration in Daphnia: a new bioassay for kairomones exuded by fish. Arch Hydrobiol 126:329-337

Manly BFJ (1974) A model for certain types of selection experiments. Biometrics 30:281-294

Meester L de (1990) Evidence for intra-population genetic variability for phototactic behavior in Daphnia magna Straus., 1820. Biol Jaarb Dodonaea 58:84-93

Parejko K, Dodson SI (1991) The evolutionary ecology of an antipredator reaction norm: Daphnia pulex and Chaoborus americanus. Evolution 45:1665-1674

Pijanowska J (1993) Diel vertical migration in zooplankton: fixed or inducible behavior? Arch Hydrobiol Beih Erg 39:89-97

Sih A (1987) Predators and prey lifestyles: an evolutionary and ecological overview. In: Kerfoot WC, Sih A (eds) Predation: direct and indirect impacts on aquatic communities, University Press of New England, pp 203-224

Spitze K (1991) Chaoborus predation and life-history evolution in Daphnia pulex: temporal pattern of population diversity, fitness and mean life history. Evolution 45:82-92

Weider LW (1984) Spatial heterogeneity of Daphnia genotypes: Vertical migration and habitat partitioning. Limnol Oceanogr 29:225-235

Weider LW (1985) Spatial and temporal genetic heterogeneity in a natural Daphnia population. J Plankt Res 7:101-123 